\title{
Violência obstétrica: Invisibilidade e enfrentamento psicológico
}

\author{
Obstetric violence: Invisibility and psychological coping \\ Violencia obstétrica: nvisibilidad y afrontamiento psicológico
}

Recebido: 06/06/2021 | Revisado: 12/06/2021 | Aceito: 16/06/2021 | Publicado: 19/06/2021

Carol Noli

ORCID: https://orcid.org/0000-0002-9040-1961 Centro Universitário Católico Salesiano Auxilium, Brasil E-mail: carolnolii@gmail.com

Isabela Ramos da Silva

ORCID: https://orcid.org/0000-0001-5272-6629

Centro Universitário Católico Salesiano Auxilium, Brasil

E-mail: isa_bgi@hotmail.com

Claudia Lopes Ferreira

ORCID: https://orcid.org/0000-0001-6105-5468

Centro Universitário Católico Salesiano Auxilium, Brasil

E-mail: claudialopes@unisalesiano.com.br

Joicimar Cristina Cozza

ORCID: https://orcid.org/0000-0003-0053-4339

Centro Universitário Católico Salesiano Auxilium, Brasil

E-mail: joice_cozza@hotmail.com

\begin{abstract}
Resumo
Compreende-se violência obstétrica qualquer ato exercido por profissionais da saúde que violem os direitos reprodutivos e sexuais de mulheres no processo gravídico-puerperal. Objetivou-se pelo estudo descritivo-exploratório de abordagem qualitativa e quantitativa, identificar o reconhecimento de 24 usuárias da rede pública enquanto gestantes, puérperas e genitoras de filhos até dois anos sobre o tema, associado ao trabalho de 8 psicólogos nos contextos socioassistenciais e de saúde do município de Birigui/SP. Resultou-se que $96 \%$ das mulheres não reconheceram a violência sofrida, entretanto, relataram práticas abusivas e atenção desumanizada. Seis psicólogos entrevistados não atenderam vítimas de violência obstétrica. Conclui-se a imprescindibilidade do olhar da psicologia na investigação e no enfrentamento da violência promovendo o empoderamento feminino e a preservação da subjetividade da mulher.
\end{abstract}

Palavras-chave: Gestação; Psicologia; Saúde pública; Violência.

\begin{abstract}
Obstetric violence is understood as any act performed by health professionals who violate the reproductive and sexual rights of women in the gravidic-puerperal process. It was aimed by the descriptive-exploratory study of qualitative and quantitative approach, to identify the recognition of 24 users of the public network as pregnant women, puerperal women and mothers of children up to two years on the theme, associated with the work of eight psychologists in the social assistance and health contexts of the city of Birigui/SP. It resulted that $96 \%$ of women did not recognize the violence suffered, however, reported abusive practices and dehumanized attention. Six psychologists interviewed did not attend to victims of obstetric violence. It was concluded that it is indispensable the look at psychology in the investigation and confrontation of violence, promoting women's empowerment and the preservation of woman's subjectivity.
\end{abstract}

Keywords: Pregnancy; Psychology; Public health; Violence.

\section{Resumen}

Se entiende por violencia obstétrica todo acto realizado por profesionales de la salud que vulnere los derechos reproductivos y sexuales de la mujer en el proceso embarazo-puerperal. El objetivo del estudio descriptivoexploratorio con enfoque cualitativo y cuantitativo fue identificar el reconocimiento de 24 usuarios de la red pública como mujeres embarazadas, madres y madres de niños hasta dos años sobre el tema, asociado al trabajo de 8 psicólogos en los contextos asistencial y sanitario del municipio de Birigui / SP. Resultó que el 96\% de las mujeres no reconocieron la violencia que sufrieron, sin embargo, denunciaron prácticas abusivas y cuidados deshumanizados. Seis psicólogos entrevistados no atendieron a víctimas de violencia obstétrica. Se concluye la indispensabilidad de la mirada psicológica en la investigación y en el enfrentamiento de la violencia promoviendo el empoderamiento femenino y la preservación de la subjetividad de la mujer.

Palabras clave: Embarazo; Psicología; Salud pública; Violencia. 


\section{Introdução}

Historicamente, as mulheres foram conhecidas como as mais passiveis vítimas da violência, entendidas como sexo frágil e destinadas a reprodução. Diante dessas circunstâncias, Guedes, Da Silva e Da Fonseca et al. (2009) declaram que a desigualdade de gênero assume um papel na constituição da civilização, colocando a mulher em uma posição social de subordinação. Para Santos e Izumino (2005), a violência contra a mulher está associada à expressão de dominação da mulher pelo homem, sucedendo anulação da autonomia da mesma. A violência de gênero ${ }^{1}$ se caracteriza por atitudes de agressão física, sexual e psicológica, que ocorrem nas relações de poder provenientes tanto das relações afetivas ou não, posto que, desconhecidos também cometem violências contra as mulheres, a chamada misoginia que se define pelo ódio, desprezo ou preconceito contra pessoas do sexo feminino que se estabelecem no âmbito da vida pública ou privada.

Dentre as violações conhecidas as quais as mulheres se encontram submetidas pode-se também destacar a violência institucional, que no âmbito da saúde constitui-se pela relação de poder hierárquica entre médico-paciente e/ou equipe. De acordo com relatos de mulheres vítimas de violência obstétrica, o protagonismo é caracterizado em muitos momentos pela equipe de saúde através de atitudes que expressam superioridade e opressão em relação ao outro (De Aguiar, D’ Oliveira \& Schraiber, et al., 2013). Discute-se a complexa causalidade de formas de violência, no final da década de 1950, relatos de violência no parto surgiram com a quebra do silêncio nos EUA, quando uma revista direcionada às mulheres publicou o texto “Crueldade nas Maternidades". O documento descrevia maneiras de como as mulheres eram submetidas a procedimentos tortuosos. Já no Brasil, o trabalho custoso das feministas produziu o pioneiro "Espelho de Vênus", que continha narrativa das experiências feministas com o parto institucionalizado.

Assim, a visibilidade do tema violência obstétrica foi despertando interesse na grande mídia (Diniz et al., 2015). Estudos apontam que no modelo tecnocrático são empregadas as práticas de violência obstétrica visto que, a violação identificada como silenciosa não se revela apenas no contato físico, mas, fatalmente acarreta sofrimento psíquico. A literatura compreende como violência obstétrica, qualquer ação praticada por profissionais de saúde que cerne ao corpo e aos processos reprodutivos e sexuais das mulheres através do abuso de ações intervencionistas, atendimento desumanizado e medicalização exacerbada. As atitudes expressas no modelo tecnocrático configuram os processos de parturição fisiológicos como patológicos (Andrade \& Aggio, 2014).

Neste sentido, teóricos integram que a saúde da mulher tem sido um campo de pertinentes discussões no decorrer dos anos. Ainda compreendem o período gestacional como um momento peculiar na vida reprodutiva das pessoas e sustentam que o nascimento de um filho é uma experiência única, sendo necessário instituir um tratamento singular e humanizado, praticado pela equipe que integram profissionais capacitados de diversos âmbitos da saúde (Vieira, Bock, Zocche \& Pessota, 2011). Segundo a literatura, o puerpério, também caracteriza um estágio de grande importância. Define-se como o período do ciclo gravídico-puerperal, que compreende o prazo de até quarenta e dois dias após o nascimento do bebê. Este momento é marcado por intensas modificações e adaptações psico-orgânicas, requerendo atenção e qualidade no atendimento para a saúde materna e neonatal.

Paes (2016) integra que o pleno direito à informação é um importante precursor no combate à desigualdade de gênero. Afirma que muitas mulheres desconhecem suas garantias legais e as intervenções que violam seus direitos. Além disso, os autores designam que é função do profissional de saúde analisar o grau de instrução da paciente para promover uma comunicação efetiva concedendo um diálogo baseado no respeito e na assistência humanizada. Nesta perspectiva, De Souza e

\footnotetext{
${ }^{1}$ Gênero é um conceito que classifica diversos fenômenos, pode ser entendido como aquilo que diferencia socialmente as pessoas. O gênero é um primeiro campo social onde o poder é articulado, assim como a raça/etnia e a classe social também são filtros de percepção e apercepção servindo de parâmetros para as relações de poder. Desta forma, o gênero pode ser também um delimitador das relações entre homens e mulheres (Carvalho, 2009P. 21-45apud Mariani; Neto, 2016 p.53).
} 
Valente (2016a), completam que o cenário de produções científicas elaboradas pela psicologia investigando a violência obstétrica é escassa em relação às suas relevantes contribuições. Dentre elas, está a desconstrução de um suposto imaginário sobre a mulher na contemporaneidade, seu empoderamento frente aos direitos humanos, políticas públicas e a preservação de sua subjetividade. Em síntese, o trabalho visou compreender o reconhecimento das mulheres sobre seus direitos reprodutivos e a violência obstétrica na região estudada. Ainda como objetivo de estudo reiterou-se a pesquisa o papel do profissional psicólogo no trabalho com mulheres vítimas de violência obstétrica e suas experiências nas áreas da saúde e psicossocial

\section{Metodologia}

Segundo Pereira, Shitsuka, Parreira e Shitsuka, (2018), a pesquisa de cunho quali-quantitativo, é um método complementar e que promove um maior entendimento entre as fenômenos de pesquisa. Assim, esta pesquisa teve como objeto de estudo gestantes, parturientes e genitoras que conceberam filhos até dois anos, assim como profissionais de psicologia exercendo a atividade nas áreas da saúde e psicossocial. A metodologia empregada consistiu na aplicação de dois instrumentos de coleta de cunho qualitativo, sendo o formulário - instrumento utilizado com a presença do entrevistador, destinado às usuárias da rede municipal de saúde sendo elas, mulheres gestantes, puérperas e genitoras com filhos até dois anos, assim como profissionais de psicologia atuantes na rede municipal. Para a coleta de dados das usuárias da rede municipal de saúde, foi aplicado um formulário impresso com questões objetivas e subjetivas, tendo como finalidade a mensuração do reconhecimento das participantes com relação ao assunto abordado.

De acordo com a normatização pertinente à pesquisa com seres humanos, o estudo atendeu aos critérios para sua realização, submetido ao Comitê de Ética em Pesquisa com Seres Humanos e aprovado sob o parecer 3.421.249. Portanto, disponibilizou-se aos participantes uma via impressa do Termo de Consentimento Livre e Esclarecido atendendo as Resoluções 466/12 e 510/16, com informações pertinentes ao estudo para autorização da coleta e divulgação dos dados, consentidos por meio das assinaturas manuscritas. As entrevistas com as mulheres ocorreram nas salas de espera das instituições Ambulatório da Criança e Unidades Básicas de Saúde do município de Birigui/SP seguindo o horário de funcionamento dos locais estabelecidos, tendo assegurado o sigilo e a confiabilidade das informações coletadas, mantendo o direito a anonimidade.

Já o recrutamento de profissionais psicólogos foi realizado a partir da autorização dos órgãos municipais de Birigui, a saber: Secretária de Saúde e a Secretária de Assistência e Desenvolvimento Social. Os questionários foram disponibilizados aos profissionais em seus contextos de atuação, sendo o Ambulatório de Saúde Mental, as Unidades Básicas de Saúde, o Centro de Referência de Assistência Social e o Centro de Referência Especializado de Assistência Social.

Desta forma, delimitou-se o prazo de dez dias para o recolhimento dos formulários e do mesmo modo assegurou-se a confiabilidade das informações coletadas mantendo o direito da anonimidade dos psicólogos. A partir dos elementos coletados realizou-se a análise descritiva e percentual do reconhecimento das usuárias sobre experiências obstétricas e a relação com as violências postuladas. Os relatos das participantes foram incluídos na pesquisa e identificados com nomes fictícios que aludem personalidades históricas do feminismo no mundo. Os profissionais foram identificados pela letra "P" seguido de números de 1 a 8, além do contexto de trabalho e tempo de atuação. O material utilizado baseou-se nas referências selecionadas por meio dos descritores científicos, de gestação, psicologia, saúde pública, e violência, obtidos pelo levantamento bibliográfico da Bireme de 2019. Assim, os resultados apresentados pelos profissionais de psicologia, também se constituíram pela análise qualitativa e quantitativa.

\section{Resultados e Discussão}

Participaram da pesquisa 24 mulheres, divididas entre gestantes que representaram 17\% da amostra e 83\% puérperas. Além disso, 66,6\% da população estudada compreendeu a faixa etária de 20 a 30 anos e $54 \%$ concluiu o ensino médio. A 
análise ao questionário sociodemográfico também apresentou que $83 \%$ das participantes vivia com companheiro, $54 \%$ trabalhava, e 50\% possuía renda de até um salário mínimo totalizando $\mathrm{R} \$ 998,00$ na época da coleta de dados. Das entrevistadas, $62,5 \%$ conceberam de um a dois filhos e 41,6\% eram pardas. Os profissionais de psicologia compuseram a amostra com oito participantes, caracterizando quatro entrevistados no contexto psicossocial, dois no Centro de Referência de Assistência Social, e dois no Centro de Referência Especializado de Assistência Social do município. Além disso, dois dos entrevistados no contexto da saúde compuseram a equipe do Núcleo de Apoio a Saúde da Família nas Unidades Básicas de Saúde e dois profissionais psicólogos do Ambulatório de Saúde Mental da cidade.

A violência obstétrica vem sendo cada vez mais utilizada em pesquisas e políticas públicas e, em 2014, passou a ser reconhecida como uma problemática pela Organização Mundial de Saúde que emitiu uma declaração intitulada "Prevenção e eliminação de abusos, desrespeito, maus-tratos durante o parto em instituições de Saúde”. Desde então, o documento recomenda diálogo, pesquisa e mobilização mundial sobre a violação de direitos humanos das mulheres. A declaração refuta atos de humilhação, violência física, abusos verbais, e procedimentos médicos coercitivos ou não consentidos, dentre outras condutas. Segundo Rodrigues (2014), a mulher deve ser protagonista de sua história, capaz de realizar escolhas sobre aquilo que diz respeito ao seu corpo. A assistência à saúde possui como dever, oferecer atendimentos adequados, que expressam segurança e profissionais especializados. Além disso, é estabelecida para a equipe que promove ações comprometidas com a fisiologia do nascimento, assim como respeitar o período de gestação, parto, amamentação, apoiados em práticas humanizadas, a qual é direito constituído das usuárias.

De acordo com as Diretrizes de Atenção à Gestante: a operação cesariana, publicada em março de 2016 pelo Ministério da Saúde, deve-se informar as mulheres grávidas sobre riscos e benefícios de uma cirurgia cesariana com a apresentação de dados atualizados de literaturas disponíveis. A medida se justifica com o intuito de promover conhecimento sobre o procedimento e viabilizar a escolha com informações adequadas. Em contrapartida, alguns estudos apontam uma crescente porcentagem em relação ao nascimento de crianças através de cirurgias cesarianas na rede privada quando equiparada com a porcentagem da rede pública. Tal realidade pode ser questionada pois em contato com mulheres gestantes a grande maioria expressa o desejo em dar à luz aos seus filhos de forma natural. Nesta pesquisa pode-se obter que $49 \%$ das puérperas escolheu a via natural de parto, contudo, 54\% foram submetidas à cirurgia cesariana, ou seja, $44 \%$ das puérperas teve de fato o nascimento pela via escolhida. Desse modo, reconhecer a violência obstétrica se torna imprescindível para que a realidade, na qual a cirurgia cesariana demonstra menor risco a gestante e ao bebê seja desmistificada tratando de ações que indique a violação de direitos da mulher (Ciello et al., 2012a).

Tostes (2016) ainda integra que o Programa de Humanização do Pré-natal e Nascimento (PHPN) instituído no ano 2000, e baseado nas recomendações da Organização Mundial da Saúde tem como objetivo garantir mudanças nos modelos de atenção, gestão e de práticas de profissionais em prudência as necessidades da população feminina, para ele:

A assistência pré-natal atende as gestantes somente em sua dimensão fisiológica, portanto, provê atenção apenas parcial às necessidades de mulheres grávidas, deixando-as desassistidas em relação a outras dimensões. Considera-se imprescindível entender melhor os aspectos sociais, psicológicos e emocionais que podem influenciar as expectativas sobre o parto, a preparação para esse momento ao longo da gestação e as vivências da parturição pelas mulheres (Tostes, 2016, p. 684).

Compreende-se que o ciclo gravídico-puerperal implica inúmeras dúvidas em relação às gestantes, nesse sentido os profissionais que compõem a equipe podem auxiliar por meio do acolhimento e da escuta qualificada, ações que buscam empoderar mulheres e torná-las participantes de forma autônoma sobre as decisões pertinentes ao parto. Um instrumento que pode contribuir para a construção dessa autonomia é o plano de parto, cujo objetivo é orientar as mulheres e seus familiares, assim como a equipe que atenderá o parto ou a cirurgia cesariana (Da Silva et.al, 2017). O resultado da pesquisa demonstrou que $83 \%$ da população entrevistada não teve acesso ao plano de parto. 
Importante destacar que essas violações são conceituadas como violência de gênero, tendo em vista que somente as mulheres podem gerar outro ser humano, desta forma, as violações são reconhecidas como Violência Obstétrica considerando, em primeiro lugar que não se trata de um tipo de violência perpetrada exclusivamente pelo médico obstetra; a expressão "abusos e desrespeitos" utilizada pela Organização Mundial da Saúde significa que tais violações ocorrerem no âmbito da assistência obstétrica e podem ser cometidos por diferente atores que atuam nos cuidados obstétricos e que podem ser reconhecidos, desde o porteiro da maternidade, passando por equipe de enfermagem até médicos, por exemplo (Ferreira, 2019, p. 229).

O plano de parto é considerado um documento com base legal, que consiste em garantir as escolhas e as decisões realizadas com a equipe de saúde em relação ao seu pré-parto, parto e pós-parto. Cabe ressaltar que o documento deveria ser fomentado no decorrer do pré-natal, sendo disponibilizado aos profissionais desde o início da parturição. Torna-se imprescindível a comunicação a parturiente caso ocorra qualquer alteração que necessite de uma intervenção distinta do que foi informado na proposta de atendimento (Da Silva et.al, 2017). Dentre as experiências, 25\% da amostra total exprimiram sentir ofendidas verbalmente pela equipe de saúde, violência caracterizada por comentários sobre as parturientes que causaram constrangimento. "Ridículo, porque no meu corpo sou eu quem mando [sic], não é ela, ela não sabe a dor que eu sinto. Então era você a escandalosa?". (L. Diniz, Janeiro, 2021).

O uso de expressões pejorativas e repressoras, por parte dos profissionais de saúde, evidencia o exercício de autoridade no ambiente institucional e são caracterizadas nas relações de gênero, o que reduz o direito das mulheres. Com a institucionalização os profissionais deixam de se comprometer com a assistência, acolhida e auxílio (Carvalho \& Brito, 2017).

Além disso, 21\% das mulheres relataram terem sido atendidas em posição ginecológica com a porta aberta e quando questionadas sobre seus sentimentos acerca da situação, Joana D'arc, de 20 anos afirmou: "Morrendo de vergonha, até pedi [sic] para sair e não saíram, eram estagiários e falaram que estavam para aprender”. (L. Diniz, Janeiro, 2021).

Para Jardim e Modena (2018) corriqueiramente nas salas obstétricas, as mulheres seminuas dividem espaço com estranhos e encontram-se sozinhas em um cenário desconhecido, além disso, são posicionadas com as pernas abertas, levantadas e a genitália amostra o que configura submissão e constrangimento. De acordo com o Dossiê "Parirás com dor", uma prática rotineira dentro das maternidades é a episiotomia conhecida como "pique" que se caracteriza como um procedimento que consiste na realização de um corte (com bisturi ou tesoura) na região do períneo, alguns vezes sem utilização de anestesia.

Após a episiotomia também é realizado 'o ponto do marido' ou (em inglês: husband'sstitch), um procedimento cirúrgico que requer uma ou mais suturas do que o necessário para reparar o períneo em decorrência da episiotomia e que afeta diversas estruturas do períneo, tendo como função a sustentação de órgãos responsáveis pela continência urinária e fecal, além de acarretar prejuízos ao clitóris (Ciello et.al., 2012b). Em 1985 a Organização Mundial de Saúde contra indicou a prática rotineira do procedimento, e reduziu de 10 a $15 \%$ o uso máximo nos casos, posto que ao invés de promover saúde genital, e assegurar a passagem do bebê, a episiotomia pode acarretar disfunções sexuais. Em comparação com os dados expressos pela pesquisa, $13 \%$ das parturientes foram submetidas ao método, e informadas após a finalização do procedimento. "Não havia a necessidade do procedimento, estava com bastante dilatação, levei oito pontos. Me senti desrespeitada, eles rasgaram minha parte íntima, hoje sinto vergonha porque minha vagina é mais aberta”. (M. Quitéria, janeiro 2021).

Destaca-se que dor perineal está relacionada com a episiotomia podendo desenvolver a dispareunia caracterizada pelo coito doloroso/laceração. Mulheres com trauma perineal relatam sentir ausência de desejo sexual, dificuldade de lubrificação, diminuição da excitação vaginal e frequência de orgasmos. Contudo, pressupõe-se que há relação do uso episiotomia com a ocorrência da dispareunia (Silva et.al, 2013). A coleta de dados também demonstrou que 25\% das entrevistadas foram submetidas à manobra de Kristller, técnica que compreende acelerar o segundo período de parto, ou seja, auxiliar a expulsão 
do feto. Embora haja poucos registros efetivos que concretizem a ineficiência da mesma, alguns autores discorreram as problemáticas provenientes desse método.

Os potenciais de riscos são fragmentados de acordo com as categorizações, mencionadas como riscos fetais e riscos maternos. A equipe médica ao utilizar desse recurso, coloca a mulher sob exposição, de produzir lacerações perianais severas, aumentar a taxa de episiotomia, assim como, aumentar a chance de parto instrumentado. Da mesma forma, podem trazer complicações ao feto como cefalohematomas, fraturas da clavícula e crânio (Carvalho, 2014). O total de 96\% das mulheres não considera os procedimentos realizados na atenção obstétrica como violentos, entretanto as ações caracterizam contradição visto que as participantes relatam sofrimento decorrente da violação de direitos pelas práticas abusivas intervencionistas e algum tipo de atenção desumanizada. É imprescindível que os governos priorizem o acesso das mulheres à informação, incluindo publicações relevantes para a garantia de direitos das mulheres e articulações que promovam acesso a essas informações.

Rodrigues (2006) refere que, a Constituição Federal de 1988 trata da função social da maternidade em diversos dispositivos, e dentre os direitos sociais, está à "proteção à maternidade" no artigo 06 , assim como os direitos previdenciários no artigo 201, II e de assistência social no artigo 203, I. A Lei $\mathrm{N}^{\circ} 15.759$, também assegura o direito da mulher ao parto humanizado nas instituições públicas de saúde do Estado e prevê outras garantias. Segundo Portela e Da Silva (2017), a violência sofrida acarreta inúmeras consequências para existência feminina. Na esfera emocional episódios traumáticos podem cooperar para a emersão de sentimentos de inferioridade, angústia, tristeza e até para o desenvolvimento de psicopatologias. Também podem inferir sobre a concepção da mulher acerca de outras gestações, sobre os profissionais de saúde e instituições hospitalares. Desta forma, considera-se significativa a intervenção da psicologia como ciência capaz de oferecer acolhimento e ressignificação do sofrimento, de modo a proporcionar a essas mulheres o cuidado e a humanização da gestação ao parto e pósparto (Wolff \& Waldow, 2008).

Quanto aos resultados obtidos das entrevistas com os profissionais de psicologia, foi possível identificar que há pouca discussão sobre o tema. A amostra desse público compreendeu em sua totalidade oito psicólogos atuantes na rede, dentre eles, seis expressaram concepções superficiais em relação ao assunto abordado e dois participantes revelaram total desconhecimento sobre violência obstétrica. Quatro psicólogos obtiveram um contato indireto com a demanda de sofrimento provindo de experiências negativas na atenção obstétrica.

Participante 1 - "Os relatos de violência obstétrica geralmente surgem em grupos socioeducativos, elas relatam que muitas se identificam, mas dizem que é normal e que nada pode ser feito”. (P1, 8 anos de formação - Centro de Referência de Assistência Social).

A literatura refere que mesmo com políticas públicas empregadas ao direito da mulher enquanto gestante e parturiente, a violência obstétrica se encontra normatizada como exemplificado no relato da participante 1. Ocorre que a falta de informação por parte dos usuários do serviço favorece o cenário de impunidade. Para os autores se faz relevante o trabalho do empoderamento feminino, tanto no Sistema Único de Saúde quanto no Sistema Único de Assistência Social, para assim sistematizar os direitos da população e reivindicá-los (De Souza \& Valente, 2016 b).

Participante 2 - "Trabalho [sic] na secretaria social, não tenho contato direto com esse tipo de situação, porém trabalho com grupos de mães que já vivenciaram dificuldades na saúde, relatam maus tratos, desrespeito, falta de acompanhamento elou orientações, assim como falta de acolhida". (P2, 5 anos de atuação - Centro de Referência de Assistência Social). 
Questionados sobre as dificuldades encontradas no contexto de atendimento psicológico às vítimas de violência obstétrica, os psicólogos entrevistados afirmaram:

Participante 3 - "Necessidade de maior integração entre os serviços de saúde, social e segurança pública, mais campanhas preventivas, melhoria, aumento no número de profissionais nos serviços e capacitação continuada em todos esses serviços". (P3, 4 anos de atuação - Centro de Referência Especializado de Assistência Social).

Participante 4 - "Ainda que não recebemos a demanda, sabemos que ela existe. A falta de informação do que é a violência já é um grande dificultador [sic] para que as mulheres se percebam enquanto vítimas e procurem ajuda e onde encontrar". (P4, 8 anos de atuação - Centro de Referência Especializado de Assistência Social).

Na saúde, a realidade também é atravessada pela invisibilidade. De Souza e Valente (2016b) apontam para os desafios políticos, institucionais e de formação encontrados na atuação da psicologia, mas também para as inúmeras possibilidades de construção de saberes, medidas de enfrentamento, de espaços de fala e de escuta das parturientes para colocação das concepções, expectativas e idealizações sobre a atenção obstétrica.

Participante 5 - "Penso haver pouquíssimos [sic] projetos em relação ao tema, assim como pouquíssimas informações tanto para os profissionais, como os usuários da saúde pública. Que haja e se faça dentro da política de saúde um programa humanizado, significativo e fundamental para a saúde mental, emocional de parturientes". (P5, 7,5 anos de atuação - NASF).

\section{Conclusão}

Compreende-se que o crescente pronunciamento das mulheres pelos movimentos sociais, políticos e pelas manifestações midiáticas tem disseminado o assunto estudado e expandido o olhar da população para a realidade do parto institucionalizado ligado a práticas abusivas realizadas por médicos, e pela equipe de saúde. Contudo, os resultados apresentados na pesquisa ainda corroboram para a concepção de invisibilidade da violência obstétrica na região, visto que as mulheres relataram ter sofrido práticas abusivas, mas não as configuraram como violência na atenção obstétrica. Tal concepção está fundamentada na naturalização dos processos tecnocráticos, na institucionalização e na desigualdade de gênero. Com base nas entrevistas, evidenciou-se que os profissionais de psicologia não atenderam diretamente a demanda elencada, e dois psicólogos apresentaram desconhecimento sobre o assunto. Desta forma, afirma-se que envolvimento da psicologia se faz necessário na construção de estratégias para o enfrentamento da violação de direitos, acolhimento e ressignificação das vivências traumáticas em prol da preservação da subjetividade da mulher. Além disso, compreende-se a necessidade de pesquisar, discutir e tornar o reconhecimento de direitos da mulher, um interesse da comunidade cientifica, já que há escassez de pesquisas nacionais, assim, a pesquisa buscou-se interligar os contextos de serviço social e saúde pública visando à contribuição na discussão cientifica a respeito da violência obstétrica sob o olhar da psicologia e erradicação da violação de direitos.

\section{Agradecimentos}

Agradecemos sobre tudo os nossos primeiros exemplos de mulheres na sociedade, nossas mães e avós, mulheres, fortes, e que mesmo por vezes fragilizadas pela vida, contribuíram para que hoje, haja em nós a realização de sonhar com um mundo com mais equidade e enxergar em outra mulher os seus direitos além das marcas adquiridas. Agradecemos, nossas 
orientadoras, mulheres e profissionais inspiradoras e que nos permitiram trilhar esse caminho tão significativo em formação humana e de contribuição cientifica.

\section{Referências}

Andrade, B. P. \& Aggio, C. M. (2014). Violência Obstétrica: A Dor Que Cala. Anais do III Simpósio Gênero e Políticas Públicas. Universidade Estadual De Londrina, Gt3- Violência Contra A Mulher e Políticas Públicas- Coord. Sandra Lourenço A. Fortuna. http://www.uel.br/eventos/gpp/pages/arquivos/gt3_briena\%20padilha\%20andrade.pdf

Carvalho, I. S. \& Brito, R. S. (2017). Formas De Violência Obstétrica Vivenciadas Por Puérperas Que Têm Parto Normal. Enfermaria Global. 16, 71-97. http://revistas.um.es/eglobal/article/view/250481

Carvalho, L. C. V. (2014). Os Efeitos Da Manobra de Kristeller no Segundo Período de Trabalho de Parto. Mestrado Em Enfermagem De Saúde Materna e Obstetrícia. https://comum.rcaap.pt/handle/10400.26/9509

Ciello, C., Carvalho, C., Kondo, C., Delage, D., Nyu, D., Werner, L.\& Santos, S. K. (2012). Parto Do Princípio. Mulheres Em Rede Pela Maternidade Ativa. Dossiê Da Violência Obstétrica "Parirás Com Dor". https://www.partodoprincipio.com.br/cartilhas.

Da Silva, A. L. N. V., Das Neves, A. B., Sgarbi, A. K. G. \& Souza, R. A. (2017). Plano De Parto: Ferramenta para o empoderamento de mulheres durante a assistência de enfermagem. Revista De Enfermagem Da Ufsm. 7,144-151. Https://Periodicos.Ufsm.Br/Reufsm/Article/View/22531.

De Aguiar, J. M., D’ Oliveira, A. F. P. L.\& Schraiber, L. B. (nov. 2013). Violência Institucional, Autoridade Médica E Poder Nas Maternidades Sob A Ótica Dos Profissionais De Saúde. Cad. Saúde Pública, 29(11). https://www.scielo.br/j/csp/a/BHJvS6SwS6DJJkY6XFTk3fs/abstract/?lang=pt

De Souza, A. C. A. \& Valente, M. B. B. (2016). Violência Obstétrica: Um Desafio Para Psicologia. Humanae-Questões Controversas Do Mundo Contemporâneo, 10(1). https://idonline.emnuvens.com.br/id/article/view/931/0

Diniz, S. G., Salgado, H. O., Andrezzo, H. F. A., De Carvalho, P. G. C, Priscila, C. A., Aguiar, C. \& Niy, D. Y. (2015). Violência Obstétrica Como Questão Para A Saúde Pública No Brasil: Origens, Definições, Tipologia, Impactos Sobre A Saúde Materna, E Propostas Para Sua Prevenção. Journal of human growth and development, 25(3), 377-384. Https://Dx.Doi.Org/10.7322/Jhgd.106080

Ferreira, C. L. (2019). Violência Obstétrica No Sistema De Justiça? In: Medeiros, A. B., \& S. S. M (Orgs.). Psicologia e Serviço Social: Referências Para O Trabalho No Judiciário.Pr: Nova Praxis Editorial.

Guedes, R. N., Da Silva, A. T. C. \& Da Fonseca, R.M. G.S. (2009). A Violência de Gênero e o Processo Saúde-Doença Das Mulheres. Esc. Anna Nery, 13, 625-631, Setembro. http://www.scielo.br/scielo.php?script=sci_arttext\&pid=s1414-81452009000300024\&lng=en\&nrm=iso

Jardim, D. M. B. \& Modena, C. M. (2018). A Violência Obstétrica No Cotidiano Assistencial e Suas Características. Rev. Latino-Am. Enfermagem, 26. https://www.scielo.br/j/rlae/a/rMwtPwWKQbVSszWSjHh45Vq/?lang=pt

Mariani, A. C. \& Neto, J. N. (2016). Violência Obstétrica Como Violência De Gênero e Violência Institucionalizada: Breves Considerações. Cad. Esc. Dir. Rel. Int. (Unibrasil) |2(25). https://portaldeperiodicos.unibrasil.com.br/index.php/anaisevinci/article/view/1107

Ministério Da Saúde. Diretrizes De Atenção À Gestante: A operação Cesariana Comissão Nacional de Incorporação de Tecnologias no Sus - Conitec. (2016). :http://Conitec.Gov.Br/Images/Relatorios/2016/Relatorio_Diretrizes-Cesariana_Final.Pdf.

Organização Mundial Da Saúde (Oms). Prevenção e eliminação de Abusos, desrespeito e Maus-Tratos durante o Parto em Instituições de Saúde. Genebra: Oms. https://www.who.Int/Reproductivehealth/Topics/Maternal_Perinatal/Statement-Childbirth/Pt/

Paes, B. Acesso À Informação e Direito das Mulheres. (2016). Artigo 19 Brasil. https://artigo19.org/wp-content/blogs.dir/24/files/2017/05/Os-5-anos-da-Leide-Acesso-\%c3\%a0-Informa\%c3\%a7\%c3\%a3o-\%e2\%80\%93-uma-an\%c3\%a1lise-de-casos-de-transpar\%c3\%aancia-1.pdf

Pereira A. S., Shitsuka, Parreira \& Shitsuka, (2018). Metodologia da pesquisa científica.Santa UFMS. https://repositorio.ufsm.br/bitstream/handle/1/15 824/Lic_Computac ao_Metodologia-Pesquisa-Cientifica.pdf?sequence=1

Portela, A. R. P.\& Da Silva, E. N. (2017). A psicologia dialogando com a Violência Obstétrica e o Direito da Mulher: Uma Revisão Bibliográfica. V Seminário Internacional Enlaçando Sexualidades. Faculdade Frassinetti do Recife. Editora, Realize. https://www.editorarealize.com.br/artigo/visualizar/30427

Rodrigues, A. (2006). (Org.) Cortês, I. (Org.). Os Direitos Das Mulheres Na Legislação Brasileira Pós-Constituinte. Centro Feminista de Estudos e Assessoria (Cfemea) -- Brasília: Letras Livres, 128. https://www.cfemea.org.br/index.php/publicacoes/4319-os-direitos-das-mulheres-na-legislacao-brasileira-posconstituinte

Rodrigues, F. A. C. (2014). Análise da Violência Institucional Contra Mulheres em processo de parturição em Maternidades da rede Cegonha de Fortaleza. Universidade Estadual do Ceará- Centro de Ciências da Saúde- Curso de Mestrado Acadêmico em Cuidados Clínicos em Saúde. Fortaleza-Ce, http://www.Uece.Br/Cmacclis/Dmdocuments/Franciscaalice.Pdf.

Silva, De Oliveira, Da Silva \& Santos. (2013). Dispareunia, dor perineal e cicatrização após episiotomia. Revista Enfermagem. Uerj. 21, . 216-220, https://www.e-publicacoes.uerj.br/index.php/enfermagemuerj/article/view/7189

Tostes, N. A. \& Seidl, E. M. F. (2016). Expectativas de Gestantes sobre o parto e suas percepções acerca da preparação para o parto. Temas Psicol. Ribeirão Preto, V. 24, N. 2, P. 681-693. http://pepsic.bvsalud.org/scielo.php?script=sci_arttext\&pid=S1413-389X2016000200015 
Research, Society and Development, v. 10, n. 7, e44110716868, 2021

(CC BY 4.0) | ISSN 2525-3409 | DOI: http://dx.doi.org/10.33448/rsd-v10i7.16868

Vieira, Bock, Zocche \& Pessota. (2011). Percepção das Puérperas sobre a assistência prestada pela Equipe de Saúde no Pré-Natal. Texto Contexto - Enferm. 20, 255-262. https://www.scielo.br/j/tce/a/Qv7s5rfV89cjFwnfrhsswRg/abstract/?lang=pt

Wolff, L. R. \& Waldow, V. R. (2008). Violência Consentida: Mulheres Em Trabalho De Parto e Parto. Saúde e Sociedade. 17(3), https://www.scielo.br/j/sausoc/a/5y44SctJDC9ZMc5bBJbYVZJ/?lang=pt

Zanardo, Uribe, De Nadal \& Habigzang. (2017). Violência Obstétrica No Brasil: Uma Revisão Narrativa. Psicol. Soc., 29. https://www.scielo.br/j/psoc/a/J7CMV7LK79LJTnX9gFyWHNN/abstract/?lang=pt 